\title{
Factors Affecting the Length of Stay in the Intensive Care Unit: Our Clinical Experience
}

\author{
Mehmet Toptas $\mathbb{D}^{\mathbb{D}},{ }^{1}$ Nilay Sengul Samanci, ${ }^{2}$ İbrahim Akkoc, ${ }^{1}$ Esma Yucetas, ${ }^{3}$ \\ Egemen Cebeci, ${ }^{4}$ Oznur Sen $\left(\mathbb{D},{ }^{1}\right.$ Mehmet Mustafa Can $\mathbb{D D}^{5},{ }^{5}$ and Savas Ozturk ${ }^{4}$
}

${ }^{1}$ Department of Anesthesiology, Haseki Training and Research Hospital, Istanbul, Turkey

${ }^{2}$ Department of Internal Medicine, Haseki Training and Research Hospital, Istanbul, Turkey

${ }^{3}$ Department of Biochemistry, Haseki Training and Research Hospital, Istanbul, Turkey

${ }^{4}$ Department of Nephrology, Haseki Training and Research Hospital, Istanbul, Turkey

${ }^{5}$ Department of Cardiology, Haseki Training and Research Hospital, Istanbul, Turkey

Correspondence should be addressed to Mehmet Toptas; dr.mehmettoptas@hotmail.com

Received 21 September 2017; Revised 28 December 2017; Accepted 18 February 2018; Published 20 March 2018

Academic Editor: Francesco Onorati

Copyright (C) 2018 Mehmet Toptas et al. This is an open access article distributed under the Creative Commons Attribution License, which permits unrestricted use, distribution, and reproduction in any medium, provided the original work is properly cited.

\begin{abstract}
Background and Aim. Long hospital days in intensive care unit (ICU) due to life-threatening diseases are increasing in the world. The primary goal in ICU is to decrease length of stay in order to improve the quality of medical care and reduce cost. The aim of our study is to identify and categorize the factors associated with prolonged stays in ICU. Materials and Method. We retrospectively analyzed 3925 patients. We obtained the patients' demographic, clinical, diagnostic, and physiologic variables; mortality; lengths of stay by examining the intensive care unit database records. Results. The mean age of the study was $61.6 \pm 18.9$ years. The average length of stay in intensive care unit was $10.2 \pm 25.2$ days. The most common cause of hospitalization was because of multiple diseases (19.5\%). The length of stay was positively correlated with urea, creatinine, and sodium. It was negatively correlated with uric acid and hematocrit levels. Length of stay was significantly higher in patients not operated on than in patients operated on $(p<0.001)$. Conclusion. Our study showed a significantly increased length of stay in patients with cardiovascular system diseases, multiple diseases, nervous system diseases, and cerebrovascular diseases. Moreover we showed that when urea, creatinine, and sodium values increase, in parallel the length of stay increases.
\end{abstract}

\section{Introduction}

Intensive care units (ICU) are high tech special treatment units that developed for close monitoring, rapid intervention, followup, and treatment of acute disease [1]. Life-threatening organ failure of chronic disease demands for intensive care beds are increasing in the world and in our country because of increasing general and aging population. We should select patients carefully because of expensive treatment and limited number of intensive care beds. Long hospital days in the intensive care units cause high costs and affect patients, their families, and the country's economy. And also longer length of stay in the ICU affects mortality. In order to improve the quality of medical care, the primary goal in intensive care is to decrease length of stay and reduce cost [2].
In our country studies about factors affecting length of stay in the intensive care units are limited. So our aim is to detect the factors associated with prolonged stays in the intensive care.

\section{Material and Methods}

2.1. Patients. In this study we retrospectively analyzed 3925 patients admitted between January 2008 and December 2014 in Haseki ICU. We obtained the patient demographic, clinical, diagnostic, and physiologic variables, mortality, and lengths of stay by examining the intensive care unit database records. The study was approved by the Ethical Committee of the Haseki training and research hospital and written 
TABle 1

\begin{tabular}{lc}
\hline & Mean \pm SD \\
\hline Age & $61.6 \pm 18.9(1-101)$ \\
Sex & \\
Men & $2185(55.7)$ \\
Women & $1740(44.3)$ \\
Operation & \\
None & $2021(51.5)$ \\
Existing & $1904(48.5)$ \\
Length of stay & $10.2 \pm 25.3(0-418)$ \\
Result & \\
Still alive & $2648(67.5)$ \\
$\quad$ Exitus & $1277(32.5)$ \\
\hline
\end{tabular}

informed consent was obtained. Exclusion criteria included patients younger than 18 years. Data input is performed by intensive care specialist.

2.2. Statistical Analysis. Statistical analyses were performed using the SPSS software (version 16.0, SPSS, Chicago. Ill). Descriptive statistics are summarized as frequencies and percentages for categorical variables and as the mean, standard deviation, minimum, and maximum for continuous variables. Mann-Whitney $U$ test was used to compare differences between two independent groups because numeric variables do not have a normal distribution. Because parametric test condition is not provided, relationships between quantitative variables were examined with Spearman Correlation Analysis. Kruskal-Wallis test was performed for groups more than two. Statistical significance was accepted at a $p$ value less than 0.05 . Determinant factors were investigated by Linear Regression Analysis Forward Method.

\section{Results}

2185 men and 1741 women were included in the total of 3925 patients who underwent hospitalization in intensive care unit. The mean age of the study was $61.6 \pm 18.9$ years (median $=65$ years). The average length of stay in intensive care unit was $10.2 \pm 25.2$ days. The median length of stay was 2 days and ranges between quarters were $1-7$ days. $48.5 \%$ of patients were operated on. The mortality rate was $32.5 \%$ (Table 1 ).

The reason of hospitalization was because of $19.5 \%$ because of multiple diseases (diabetes mellitus, hypertension, vasculitis, etc.), $16.8 \%$ cerebrovascular diseases, $13 \%$ gastrointestinal diseases, $9.5 \%$ respiratory disease, cardiovascular diseases 9\%, 8.7\% urogenital diseases, 6.8\% musculoskeletal diseases, $4.9 \%$ hepatobiliary diseases, and $3.7 \%$ endocrine diseases. Biochemical parameters are summarized in Table 2.

The length of stay was positively correlated with urea, creatinine, and sodium. It was negatively correlated with uric acid and hematocrit levels ( $p<0.001$, rho: $0.180 ; p<0.001$, rho: $0.154 ; p=0.002$, rho: $0.049 ; p=0.024$, rho: -0.282 ; $p=0.048$, rho: -0.032 ) (Table 3 ). There was no statistically significant difference between sexes ( $p=0.873$ ). ICU stay day was significantly higher in patients not operated on than in patients operated on $(p<0.001)$. The stay day in ICU was longer in patients with multiple diseases $(16.1 \pm 30.4, p<$ $0.001)$.

In univariate analysis in models that are created from variables of $p<0.100$, urea, AST, sodium levels, cardiovascular system diseases, multiple diseases, nervous system diseases, and cerebrovascular diseases were identified as factors that determine the length of stay (Table 4).

\section{Discussion}

The characteristics of prolonged ICU stay would be useful, if some factors could be modified. These factors should include process of care, active relevance of ICU physicians, and length of hospital stay before ICU admission. And so patients with long length of stay and thus high costs can be identified early $[3,4]$.

In intensive care units to measure disease severity they use many scoring systems consisting of various parameters. APACHE II is one of this scoring systems [5]. APACHE II scoring system is considered to show good correlation with the risk of mortality and hospital-acquired infections [6]. We did not use APACHE scoring systems because our aim is not to predict the mortality; in this study we want to predict prolonged length of stay.

Our study showed a significantly increased length of stay in patients with cardiovascular system diseases, multiple diseases, nervous system diseases, and cerebrovascular diseases. In a prospective study by Wong et al., for patients in ICU, the most common reasons for admission were neuromuscular weakness, pneumonia, multiple traumas, and septic shock, in this order. Respiratory arrest, cardiac arrest, congestive heart failure, postoperative mechanical ventilation, airway protection or obstruction, and chronic obstructive pulmonary disease were the next most common indications for ICU admission in these patients [7].

And in one study, postoperative patients' length of stay in ICU was shorter than that of patients admitted to the ICU for other reasons [8]. Similarly our study showed that length of stay was significantly higher in patients not operated on than in patients operated on.

Making changes in any of the medical factors about illness which affect length of stay needs expert medical skills $[9,10]$. And also psychological, social, and institutional factors have effect on ICU length of stay $[2,11]$ Ahrens et al. found that when a specialized team consisting of a physician and a clinical nurse specialist works in ICU, the length of stay would be shorter [12]. But we did not study this area.

Our study showed that when urea, creatinine, and sodium values increase, in parallel the length of stay increases. This means that physicians should pay attention to kidney injury and rehydration.

Also there are social and psychological factors that affect the length of stay, but we want to emphasize the medical factors. 
TABLE 2

\begin{tabular}{lccc}
\hline & Mean \pm SD & Min & Max \\
\hline Urea & $64.0 \pm 56.4$ & 5 & 565 \\
Creatinine & $1.7 \pm 2.0$ & 0.1 & 25.7 \\
Uric acid & $5.4 \pm 3.0$ & 1 & 13 \\
Albumin & $2.7 \pm 0.7$ & 1 & 9 \\
LDH & $519.0 \pm 1074.7$ & 3 & 20540 \\
AST & $158.0 \pm 591.1$ & 0 & 9657 \\
ALT & $116.5 \pm 338.7$ & 1 & 3666 \\
Sodium & $138.1 \pm 6.2$ & 89 & 192 \\
Hematocrit & $33.4 \pm 7.1$ & 7 & 83 \\
Hemoglobin & $11.0 \pm 2.4$ & 2 & 25 \\
Platelet & $239.2 \pm 130.4$ & 2 & 3258 \\
WBC & $13.5 \pm 8.6$ & 0 & 170 \\
\hline
\end{tabular}

LDH: lactate dehydrogenase; AST: aspartate dehydrogenase; ALT: alanine dehydrogenase; WBC: white blood cells.

TABLE 3

\begin{tabular}{lcc}
\hline & \multicolumn{2}{c}{ Length of stay } \\
& rho & $p$ \\
\hline Age & 0.026 & 0.107 \\
Urea & 0.180 & $<0.001$ \\
Creatinine & 0.154 & $<0.001$ \\
Uric acid & -0.282 & 0.024 \\
Albumin & 0.014 & 0.568 \\
LDH & -0.022 & 0.396 \\
AST & -0.040 & 0.076 \\
ALT & 0.023 & 0.373 \\
Sodium & 0.049 & 0.002 \\
Hematocrit & -0.032 & 0.048 \\
Hemoglobin & -0.028 & 0.087 \\
Platelet & 0.003 & 0.864 \\
WBC & 0.011 & 0.498 \\
\hline
\end{tabular}

LDH: lactate dehydrogenase; AST: aspartate dehydrogenase; ALT: alanine dehydrogenase; WBC: white blood cells.

TABLE 4

\begin{tabular}{lccc}
\hline & $B$ & Beta & $p$ \\
\hline Constant value & $-16,355$ & & \\
Operation & $-9,925$ & $-0,134$ & $<0,001$ \\
Urea & $-0,046$ & $-0,087$ & $<0,001$ \\
Sodium & 0,278 & 0,059 & 0,014 \\
AST & $-0,003$ & $-0,052$ & 0,029 \\
Cardiovascular system & 9,286 & 0,081 & 0,002 \\
Multiple disease & 6,107 & 0,078 & 0,004 \\
Cerebrovascular disease & 9,302 & 0,103 & $<0,001$ \\
\hline
\end{tabular}

AST: aspartate dehydrogenase. Uric acid was not included in the model because of insufficient number.

\section{Conclusion}

Our study showed a significantly increased length of stay in patients with cardiovascular system diseases, multiple diseases, nervous system diseases, and cerebrovascular diseases.
Moreover we showed that when urea, creatinine, and sodium values increase, in parallel the length of stay increases. Further studies could supply a strategy for targeting the specific risk factors.

\section{Conflicts of Interest}

The authors have declared that no conflicts of interest exist.

\section{References}

[1] T. L. Higgins, W. T. McGee, J. S. Steingrub, J. Rapoport, S. Lemeshow, and D. Teres, "Early indicators of prolonged intensive care unit stay: Impact of illness severity, physician staffing, and pre-intensive care unit length of stay," Critical Care Medicine, vol. 31, no. 1, pp. 45-51, 2003.

[2] D. A. Gruenberg, W. Shelton, S. L. Rose, A. E. Rutter, S. Socaris, and G. McGee, "Factors influencing length of stay in the intensive care unit," American Journal of Critical Care, vol. 15, no. 5, pp. 502-509, 2006.

[3] E. Ceylan, I. Oya, A. Gülsüm, E. Hülya, S. U. Eyüp, and A. Atila, "İç Hastalıkları Yoğun Bakım Ünitesinde izlenmiş Hastalarda Mortalite ve Morbiditeyi Etkileyen Faktörler," Toraks Dergisi, vol. 2, pp. 6-12, 2001.

[4] E. Ely, S. Gautam, R. Margolin et al., "The impact of delirium in the intensive care unit on hospital length of stay," Intensive Care Medicine, vol. 27, no. 12, pp. 1892-1900, 2001.

[5] K. M. Ho, G. J. Dobb, M. Knuiman, J. Finn, K. Y. Lee, and S. A. Webb, "A comparison of admission and worst 24-hour acute physiology and chronic health evaluation II scores in predicting hospital mortality: a retrospective cohort study," Critical Care, vol. 10, p. R4, 2006.

[6] J.-Y. Fagon, J. Chastre, A. Vuagnat, J.-L. Trouillet, A. Novara, and C. Gibert, "Nosocomial pneumonia and mortality among patients in intensive care units," Journal of the American Medical Association, vol. 275, no. 11, pp. 866-869, 1996.

[7] D. T. Wong, M. Gomez, G. P. McGuire, and B. Kavanagh, "Utilization of intensive care unit days in a canadian medicalsurgical intensive care unit," Critical Care Medicine, vol. 27, no. 7, pp. 1319-1324, 1999. 
[8] M. Hughes, F. N. MacKirdy, J. Norrie, and I. S. Grant, "Outcome of long-stay intensive care patients," Intensive Care Medicine, vol. 27, no. 4, pp. 779-782, 2001.

[9] K. L. Brown, D. A. Ridout, A. P. Goldman, A. Hoskote, and D. J. Penny, "Risk factors for long intensive care unit stay after cardiopulmonary bypass in children," Critical Care Medicine, vol. 31, no. 1, pp. 28-33, 2003.

[10] S. G. De Hert, P. J. Van Der Linden, S. Cromheecke et al., "Choice of primary anesthetic regimen can influence intensive care unit length of stay after coronary surgery with cardiopulmonary bypass," Anesthesiology, vol. 101, no. 1, pp. 9-20, 2004.

[11] O. V. Hein, J. Birnbaum, K. Wernecke, M. England, and W. Konertz, "Prolonged intensive care unit stay in cardiac surgery: Risk factors and long-term-survival," The Annals of Thoracic Surgery, vol. 81, no. 3, pp. 880-885, 2006.

[12] T. Ahrens, V. Yancey, and M. Kollef, "Improving family communications at the end of life: implications for length of stay in the intensive care unit and resource use," American Journal of Critical Care, vol. 12, no. 4, pp. 317-323, 2003. 


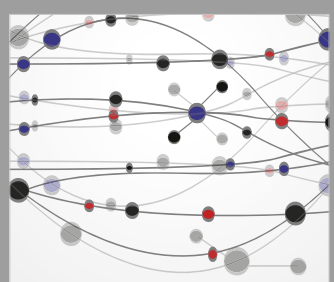

The Scientific World Journal
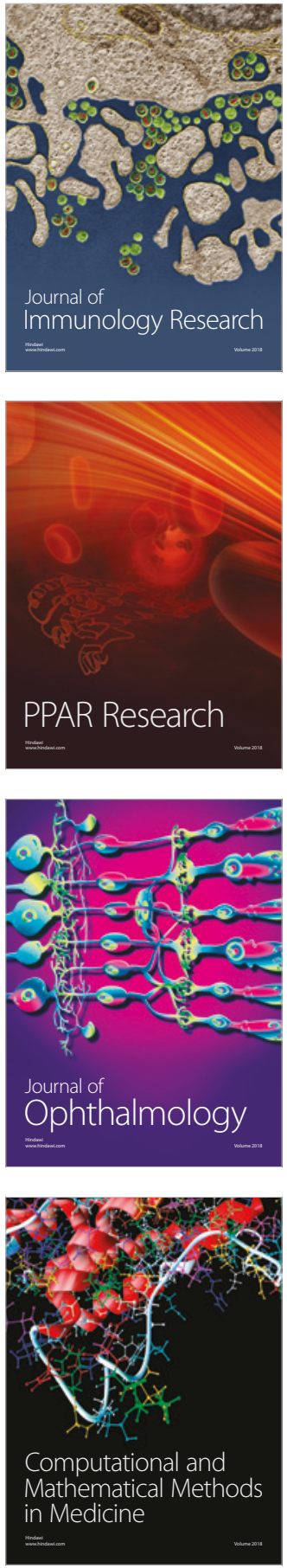

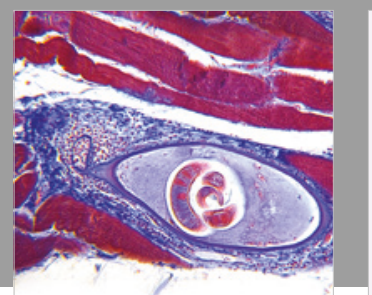

Gastroenterology Research and Practice

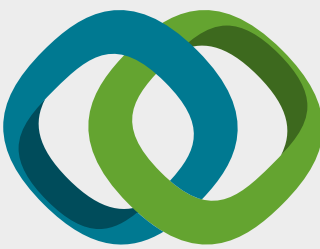

\section{Hindawi}

Submit your manuscripts at

www.hindawi.com
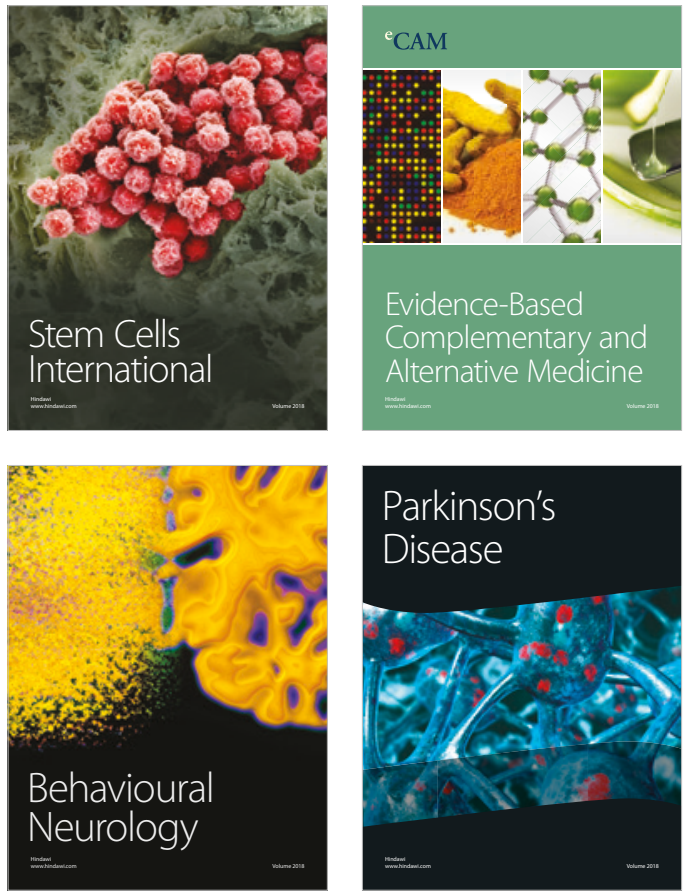

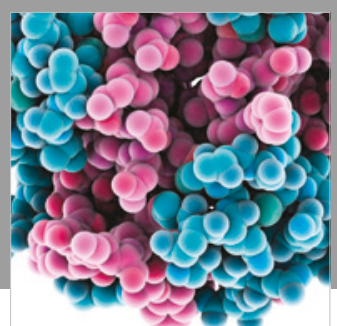

ournal of

Diabetes Research

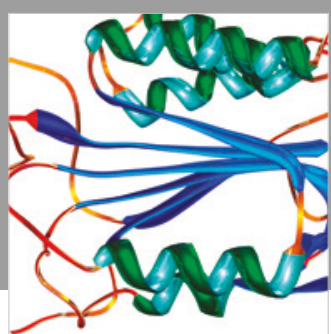

Disease Markers
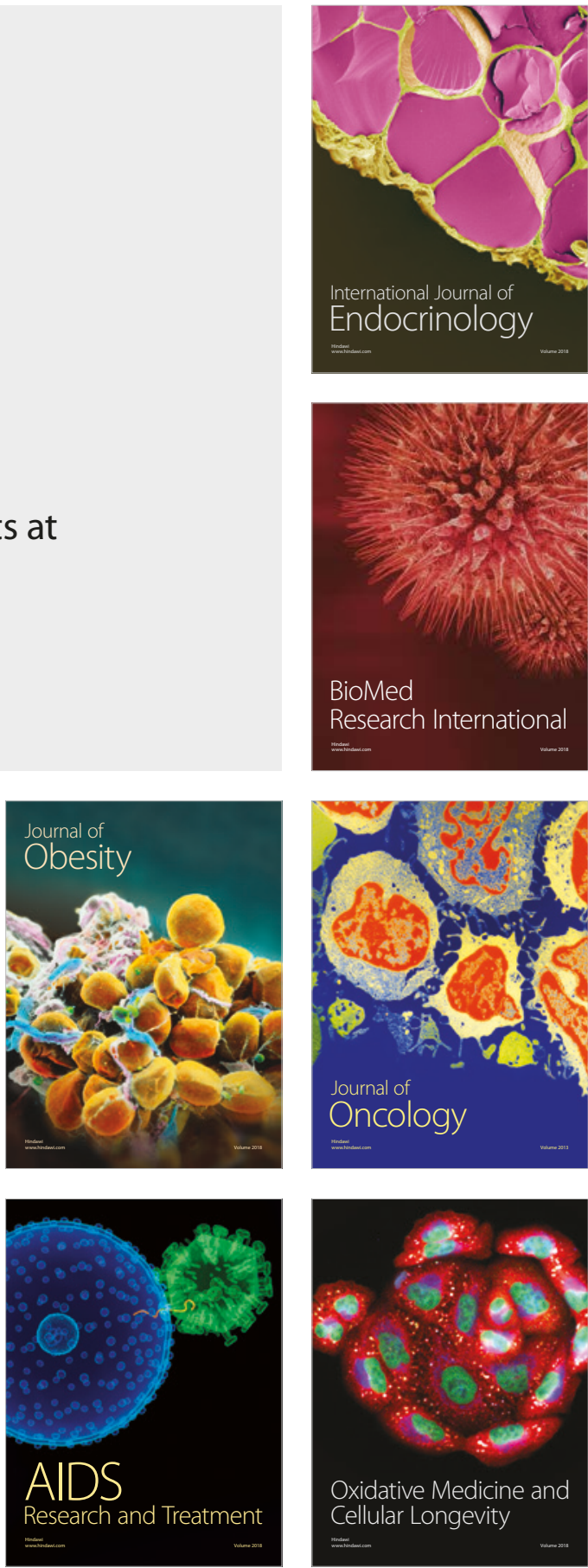